\title{
Development of a Model for Recurrent Tonsillitis in Paediatric Patient
}

\author{
Omolola Abike Akintola ${ }^{1}$, Samuel Ademola Adegoke ${ }^{2}$, Adanze Onyenonachi Asinobi ${ }^{3}$, \\ Temilade Aderounmu ${ }^{4}$, Victor Oluwatimilehin Adebayo ${ }^{1}$, Peter Adebayo Idowu ${ }^{1}$ \\ ${ }^{1}$ Department of Computer Science \& Engineering, Obafemi Awolowo University, Ile-Ife, Nigeria \\ ${ }^{2}$ Department of Pediatrics and Child Health, Obafemi Awolowo University, Ile-Ife, Nigeria \\ ${ }^{3}$ Department of Pediatrics, College of Medicine, University of Ibadan, Ibadan, Nigeria \\ ${ }^{4}$ Department of Pediatrics and Child Health Care, Obafemi Awolowo University Teaching Hospital Complex, Ile-Ife, Nigeria
}

Email address:

paidowu1@yahoo.com (P. A. Idowu)

\section{To cite this article:}

Omolola Abike Akintola, Samuel Ademola Adegoke, Adanze Onyenonachi Asinobi, Temilade Aderounmu, Victor Oluwatimilehin Adebayo, Peter Adebayo Idowu. Development of a Model for Recurrent Tonsillitis in Paediatric Patient. Clinical Medicine Research.

Vol. 8, No. 5, 2019, pp. 101-114. doi: 10.11648/j.cmr.20190805.13

Received: July 14, 2019; Accepted: August 5, 2019; Published: October 12, 2019

\begin{abstract}
This study identifies the risk factors of recurrent tonsillitis in pediatric patient which in turn are the variables used in developing a predictive model for predicting the risk of recurrent tonsillitis. This is achieved by eliciting knowledge on the risk factors of recurrent tonsillitis, formulating the model using the variables and simulating the model using MATLAB tool. Interviews were conducted with the pediatrician and existing literature was studied on the knowledge of study in order to identify the variables for recurrent tonsillitis. Seven (7) data from tonsillitis patients were collected from Wesley Guild Hospital, Ilesha. Predictive model was formulated using the fuzzy logic model and simulated on MATLAB R2016a. Fuzzy logic was used as the predictive model to determine the risk of recurrent tonsillitis. The stages involved in the process are four (4) which includes: fuzzification, rule production, aggregation and defuzzification. The identified variables were given crisp values and within a membership function of 0 and 1 . The simulated result of the fuzzy logic model was done using MATLAB which involved formulation of the fuzzy logic inference system (FIS) which was carried out by the MATLAB tool. The variables which are the risk factors were used to build the fuzzy logic inference system (FIS) to determine the risk of recurrent tonsillitis. Possible combinations of rules were given for the variables and the rules were used in the inference engine to predict the output of the model whether it is no, low, moderate or high risk of recurrent tonsillitis. The validation was done on the data gotten from Wesley Guild Hospital Ilesha from 7 patients. In conclusion, out of the seven (7) patients test data provided, five (5) patients have low risk, two (2) patients have moderate risk, no patients have no low risk and no patients have high risk of recurrent tonsillitis with $100 \%$ test accuracy.
\end{abstract}

Keywords: Recurrent Tonsillitis, Model, Pediatric Patient, Fuzzy Logic, Inference System

\section{Background}

Tonsils are collection of lymphoid tissue located in the pharyngeal cavity and the set of lymphatic tissue includes the pharyngeal tonsil (adenoids), two tubal tonsils, two palatine tonsils and the lingual tonsil [1]. Their function is to filter and protect the respiratory and alimentary tracts from invasion by pathogenic organism. They also have a role in antibody formation [2]. Tonsillitis is inflammation of the tonsils caused by a bacterial or viral infection [3]. Most common causes of tonsillitis may be due to viruses such as adenovirus, rhinovirus, Influenza, corona virus and respiratory syncytial virus. It can also be caused by the Epstein-Barr virus, herpes simplex virus, cytomegalovirus or HIV. The most common bacterial cause is Group A betahaemolytic streptococcus (GABHS) which is referred to as strep throat [4].

In children, sore throat may be part of the early symptom complex of upper respiratory tract morbidity. Although adults too suffer from the inflammation, tonsillitis is more common 
in children [5]. Group A streptococcus viruses that cause common cold or influenza are said to be the main causes of tonsillitis [6]. Tonsillitis is contagious and can be passed to another person through coughing, sneezing and sharing of household utensils such as cups and spoons, especially if not sterilised [7].

In a study by Ali and Al-Shehri [8] to evaluate the incidence of postoperative tonsillectomy haemorrhage (PTH) and to identify the possible risk factors associated with its occurrence, four hundred seventy-seven (477) patients had tonsillectomy from January 2008 to December 2013. The indication for tonsillectomy in $394(82.6 \%)$ was recurrent tonsillitis.

A comparative study of bacteriology in recurrent tonsillitis among children and adults says that the diagnosis and treatment of acute tonsillitis are one of the most common problems seen at an otolaryngology clinic in both adult and paediatric population [9]. Tonsillitis appear to constitute 5$10 \%$ of the measurable illness from all causes and from 15 $20 \%$ of illnesses due to respiratory diseases [10].

A research conducted by Vijayashree et al. [11] studied the occurrence of acute tonsillitis with respect to population distribution and was found to vary differently. Among the reported age groups, maximum tonsillitis cases were observed in the preteen age group (6-12 years) with $61 \%$ followed by teen age groups (12-18 years) $20 \%$, children $(4-5$ years) $10 \%$ and the least incidence of $9 \%$ in youth (19-30 years).

About 30 million children develop tonsillitis with frequent exposure to bacterial and viral infections. About one out of ten children visit doctor for tonsillitis in each year. Recurrent tonsillitis has an incidence in general practice in the UK of 100 per 1000 population a year [12].

A study was carried out by [13] on total number of 60 children (49 female and 11 male) attending Hail university nursery in Hail city. The age of the study group ranged from 4 months - 5 years. Forty children have a history of tonsillitis, $40(66.7 \%)$ children were infected with tonsillitis.

In today's world, technology play an important role in every industry as well as in our personal lives. Out of all the industries that technology plays a crucial role in, healthcare is definitely one of the most important. It is responsible for improving and saving countless lives all around the world [14]. Developments and technology improvements in the health sector is at global level. i.e. most of the technology is getting shared easily and doctors in the remote areas are also getting technology updates in health sector. The increased technology is not only confined to doctors or instruments they use. People are using android and ios applications for health tips and they are learning effective and efficient methods to prevent diseases [15].

Predictive modelling involves the process of predicting members according to their relative risk [16]. In this study, there is need for the prediction of recurrent tonsillitis in paediatric patients so that early detection will be possible and proper measure will be taking for the treatment of the disease and also to reduce morbidity rate in the country.
In Nigeria, there is no model that can be used to forecast recurrent tonsillitis and as a result there is a need to develop a model to assist both the patient and paediatrician in order to find out the possibility of occurrence of tonsillitis. This is the focus of this paper.

\section{Related Works}

In a research work by Van-Staaij et al. [2], a group of children with recurrent symptoms of Upper Respiratory Infection (URI) were selected and univariate and multivariate logistic regression modelling was used to evaluate which information obtained from medical history, physical examination, and laboratory tests independently contributed to the prediction of chronic recurrent URI. Using the regression coefficients of the final predictive model, the risk score of developing chronic recurrent URI was calculated and estimated for each child. The probability of developing chronic recurrent URI was calculated to be $76 \%$ of 230 children that was examined. This study was limited to the use of regression modelling in the prediction of chronic recurrent upper respiratory infections in children.

A study by Butler et al [17] in predicting the clinical course of suspected acute viral upper respiratory tract infection in children used regression analysis using Canadian respiratory illness and flu scale data from a randomized controlled trial cohort of children aged from 6 months to 12 years consulting in general practice with suspected acute viral upper respiratory tract infection. It was used to identify features available on the day of consulting that might predict a prolonged clinical course among children with suspected acute viral upper respiratory tract infection. Two variables from the clinician's records ('age' and 'cough') and two variables from the Canadian respiratory illness and flu scale completed by carers on the day of consulting ('fever' and 'low energy, tired') explained approximately $15 \%$ of the variation present in Canadian respiratory illness and flu scale scores on day seven. It is limited to the use regression modelling.

In a research work by Moore et al. [19] used logistic regression in the prediction of pneumonia in lower respiratory tract infections. The explanatory variables assessed were patient characteristics (age, gender, social deprivation and medical history). The diagnostic value of combining statistically predictive variables was assessed by including them in a statistical model, starting with the most predictive and then sequentially adding in the variables that most increased the area under the receiver operating curve (AUC) Oxygen saturation is regarded as normal if in the range of $95-99 \%$ and so values were dichotomised at $<95 \%$. Temperature is regarded as normal up to $37.7^{\circ} \mathrm{C}$ and so values were dichotomised at $\geq 37.8^{\circ} \mathrm{C}$. The limitation of the study was absence of prior training or standardisation of recorded history or clinical signs and had no quality assurance for examination findings.

A research work by Cohen et al. [19] in multi centre, prospective, cross-sectional study, French primary care physicians collected clinical data and double throat swabs 
from 676 consecutive children with pharyngitis. A logistic regression model was developed combining signs and symptoms with GAS as the outcome. A model-based selective testing strategy was derived, assuming that children with low and high calculated probability of GAS $(<0.12$ and $>0.85$ ) would be managed. Out of 17 candidate signs and symptoms, eight were retained in the prediction model. The model had an optimism-corrected c-index of 0.73 ; calibration of the model was good. With the model-based strategy, Rapid antigen detection test could be avoided in $6.6 \%$ of participants ( $95 \%$ confidence interval $4.7 \%$ to $8.5 \%$ ), as compared to a rapid antigen detection test -for-all strategy. The study was limited to logistic modelling procedures for developing and evaluating the clinical prediction model as there exists other methods.

In a study by Aalbers et al. [20], they sought to assess the diagnostic accuracy of signs and symptoms and validate a clinical prediction rule (CPR), the Centor score, for predicting group A $\beta$-haemolytic streptococcal (GABHS) pharyngitis in adults ( $>14$ years of age) presenting with sore throat symptoms. Bivariate random effects model were used to analyse the extracted data. As a decision rule for considering antibiotic prescribing (score $\geq 3$ ), the Centor score has reasonable specificity $(0.82,95 \%$ CI 0.72 to 0.88$)$ and a post-test probability of $12 \%$ to $40 \%$ based on a prior prevalence of $5 \%$ to $20 \%$. The limitation of this study is that it compares the proportion of patients predicted and observed to have GABHS pharyngitis but without patient level data.

A research work by Attia [21] showed the study of 297 children presented to the ED with pharyngitis, standardized throat cultures were performed and 12 demographic and clinical variables were recorded for each child. Cultures were positive in $85(29 \%)$ and negative in $212(71 \%)$; the mean ages of the two groups were 6.2 and 6.1 years, respectively. Four of the clinical variables were found to be independent predictors of GABHS (Group A beta-haemolytic streptococcal) pharyngitis: scarlatiniform rash, moderate to severe tonsillar swelling, moderate to severe tenderness and enlargement of cervical lymph nodes, and absence of moderate to severe coryza. When all four variables were present, the probability of GABHS was $95 \%$. The study is limited to the use of multivariate predictive model.

In summary, the related works discussed above focused on upper respiratory infections, pharyngitis and lower respiratory infections with the use of logistic regression modelling, bivariate random effects model and multivariate predictive model respectively. This current study focuses on predicting recurrent tonsillitis in paediatric patient with the use of fuzzy logic model which is a different approach from what was used for the related works.

\section{Methods}

This research requires the development of a predictive model for the recurrence of tonsillitis in paediatric patients. The risk factors of recurrent tonsillitis in paediatric patients represented the variables used for the development of the predictive model and fuzzy logic was used to formulate the predictive model.

\subsection{Variable Description}

In this study, variables were identified followed by a structured interview with a paediatrician and also through the study of existing literature on the body of knowledge of the risk of recurrent tonsillitis in paediatric patients. The detailed description of the variables includes the following.

1. Age: it describes the age of the patient and it is recorded as a numeric value which determines the age in years.

2. Parental smoking: it describes whether the parent of the patient smokes, it is Yes or No.

3. Gender: it describes if the patient is male or female, it is Yes or No

4. History of throat infections: it describes if the patient has had throat infections in the previous year, it is recorded as a numeric value.

5. Number of older siblings: it describes the number of older sibling the patient has, it is recorded has numeric value.

6. History of Upper Respiratory Infections (URI): it describes the number of URI the patient has in the previous year, it is recorded in numerical value.

7. Difficulty breathing at night: it describes the breathing difficulty the experienced by the patient at night, it is Yes or No.

Following the identification and the simulation of the variables that were needed for the prediction of recurrent tonsillitis based on the values of the identified variables, there was the need for the collection of data from patients required for the validation of the proposed model for recurrent tonsillitis. Therefore, using structured questionnaires, data were collected from 77 patients of Wesley Guild Hospital, Obafemi Awolowo University Teaching hospital, Nigeria.

\subsection{Fuzzy Logic Model for the Prediction of Recurrent Tonsillitis}

In the prediction of recurrent tonsillitis, there is a need to make a general description of the mathematical model of the proposed fuzzy logic that was used. The mathematical model of the fuzzy logic was used to generate the membership functions that was used to map the labels of each variable to their respective fuzzified value using a process called fuzzification. The triangular membership was used in fuzzifying both the input and output variables. The function maps the linguistic value (label) of each variable using a triangular-shaped function which uses three points to define two base points and one apex point.

The mathematical representation of the triangular membership function used to map the linguistic values (labels) of each variable (input and output). The mathematical model for any given triangular membership function with base points a and $c$ with an apex $b$ within the interval $(a, c)$ where $b$ lies between a and $c$ such that $a, b$ and 
c are real numbers is shown below:

$$
f(x ; a, b, c)=\left\{\begin{array}{c}
0, x \leq a \\
\frac{x-a}{b-a}, a \leq x \leq b \\
\frac{c-x}{c-b}, b \leq x \leq c \\
0, c \leq x
\end{array}\right\}
$$

or more compactly by the expression:

$$
\mathrm{f}(\mathrm{x} ; \mathrm{a}, \mathrm{b}, \mathrm{c})=\max \left(\min \left(\frac{x-a}{b-a}, \frac{c-x}{c-b}\right), 0\right.
$$

The parameters a and c depict the feet of the triangle and the parameter $b$ locates the peak of the triangle. The membership function maps each element of $\mathrm{X}$ to $\mathrm{a}$ membership value between 0 and 1 .

i. Fuzzification Process in the Fuzzy Logic Model

The fuzzy logic model for the prediction of recurrent tonsillitis involves a number of processes which are; fuzzification, rule production, aggregation of rules and the defuzzification of the results of the aggregated membership function.

The first process in the modelling of a fuzzy logic system is fuzzification. The first step in the modelling of the controller is data fragmentation (fuzzification) into input that can be accepted by fuzzy logic. Fuzzification converts each unit of input data to a degree of membership by calling on some membership function in the MATLAB fuzzy logic toolbox. For the purpose of this research work, the triangular membership function of the fuzzy logic toolbox was used in developing the membership function degrees of the labels of each variable used for input and output variables.

The variables serve as the input to the fuzzy logic model for determining recurrent tonsillitis while the overall risk is identified as the output variable. Table 1 give a description of the fuzzification of inputs variables of recurrent tonsillitis using the mathematical model in equation 3.1 to plot the respective fuzzified values for their individual labels using the crisp interval. The different fuzzified inputs were fed to their respective inference engines which contains the rule base of the recurrent tonsillitis. The rule base is a combination of the different labels of the variables identified. The inference engine is the part of the fuzzy logic inference system which combines the values of variables presented after fuzzification after which the process of defuzzification is performed in determining the value of the risk of recurrent tonsillitis as output.

\begin{tabular}{|c|c|c|c|c|}
\hline $\mathbf{S} / \mathbf{N}$ & Variable & Linguistic variable & Crisp Interval & Input \\
\hline \multirow{2}{*}{1} & \multirow{2}{*}{ Age } & 4 years or more & $-0.5,0,0.5$ & 0 \\
\hline & & Below 4 years & $0.5,1,1.5$ & 1 \\
\hline \multirow{2}{*}{2} & \multirow{2}{*}{ Parental smoking } & No & $-0.5,0,0.5$ & 0 \\
\hline & & Yes & $0.5,1,1.5$ & 1 \\
\hline \multirow{2}{*}{3} & \multirow{2}{*}{ Gender } & Female & $-0.5,0,0.5$ & 0 \\
\hline & & Male & $0.5,1,1.5$ & 1 \\
\hline 4 & History of throat infections & Below 2 times & $-0.5,0,0.5$ & 0 \\
\hline \multirow{2}{*}{5} & \multirow{2}{*}{ Number of older siblings with disease } & None & $-0.5,0,0.5$ & 0 \\
\hline & & 1 or more & $0.5,1,1.5$ & 1 \\
\hline \multirow{2}{*}{6} & \multirow{2}{*}{ History of upper respiratory infections } & below 6 & $-0.5,0,0.5$ & 0 \\
\hline & & 6 or more & $0.5,1,1.5$ & 1 \\
\hline \multirow{2}{*}{7} & \multirow{2}{*}{ Difficulty breathing at night } & No & $-0.5,0,0.5$ & 0 \\
\hline & & Yes & $0.5,1,1.5$ & 1 \\
\hline
\end{tabular}

Table 1. Fuzzification of Recurrent Tonsillitis Inputs.

\section{ii. Fuzzification of Output}

There are seven (7) variables used for the formulation of the predictive model which is equivalent to seven points. i.e. 7 variables $=7$ points. In the risk of recurrent tonsillitis, there are degree of risk, namely; no risk, low risk, moderate risk and high risk. Table 2 shows the value equivalent to each of the degree of the risk.

$$
\text { risk of tonsillitis }=\left\{\begin{array}{c}
\text { No risk } \\
\text { Low risk } \\
\text { Moderate risk } \\
\text { High risk }
\end{array}\right.
$$

iii. Rule Production for the Fuzzy Logic Model

The rule production is the second process after fuzzification. In this stage, the truth value for each rule was computed and then applied to the corresponding part of each rule. The rule-based system for the controller uses two input variables and output variable as the conditions and the conclusion of the rules.

If (Age $=">4 ")$ AND (Parental Smoking = "No") AND $($ Gender $=$ "Female") AND (History of throat infections $=$ " $\leq$ 2") AND (Older Siblings = "0") AND (History of URI Infections $=$ " $\leq 6 "$ ") AND (Difficulty in breathing at night $="$ No") THEN (Recurrent Tonsillitis = "No Recurrence"). There were 128 rules created in total for determining the risk of recurrent tonsillitis in paediatric patients as shown in figure 1 .

iv. Rule Production

If (var $1=$ label) AND (var $2=$ label) .... AND (var $n$ $=$ label) THEN $($ Risk = label $)$

Possible number of rules $=2 \times 2 \times 2 \times 2 \times 2 \times 2 \times 2=128$

$$
\text { Age }=\frac{128}{2}=64
$$

Parental smoking $=\frac{64}{2}=32$

$$
\text { Gender }=\frac{32}{2}=16
$$


Table 2. Fuzzification of Output.

\begin{tabular}{lll}
\hline Class & Interval & Interval \\
\hline No risk & 0 & $-0.5,0,0.5$ \\
Low risk & $1-2$ & $0.5,1,1.5$ \\
Moderate risk & $3-5$ & $1.5,2,2.5$ \\
High risk & $6-7$ & $2,5,3,3.5$ \\
\hline
\end{tabular}

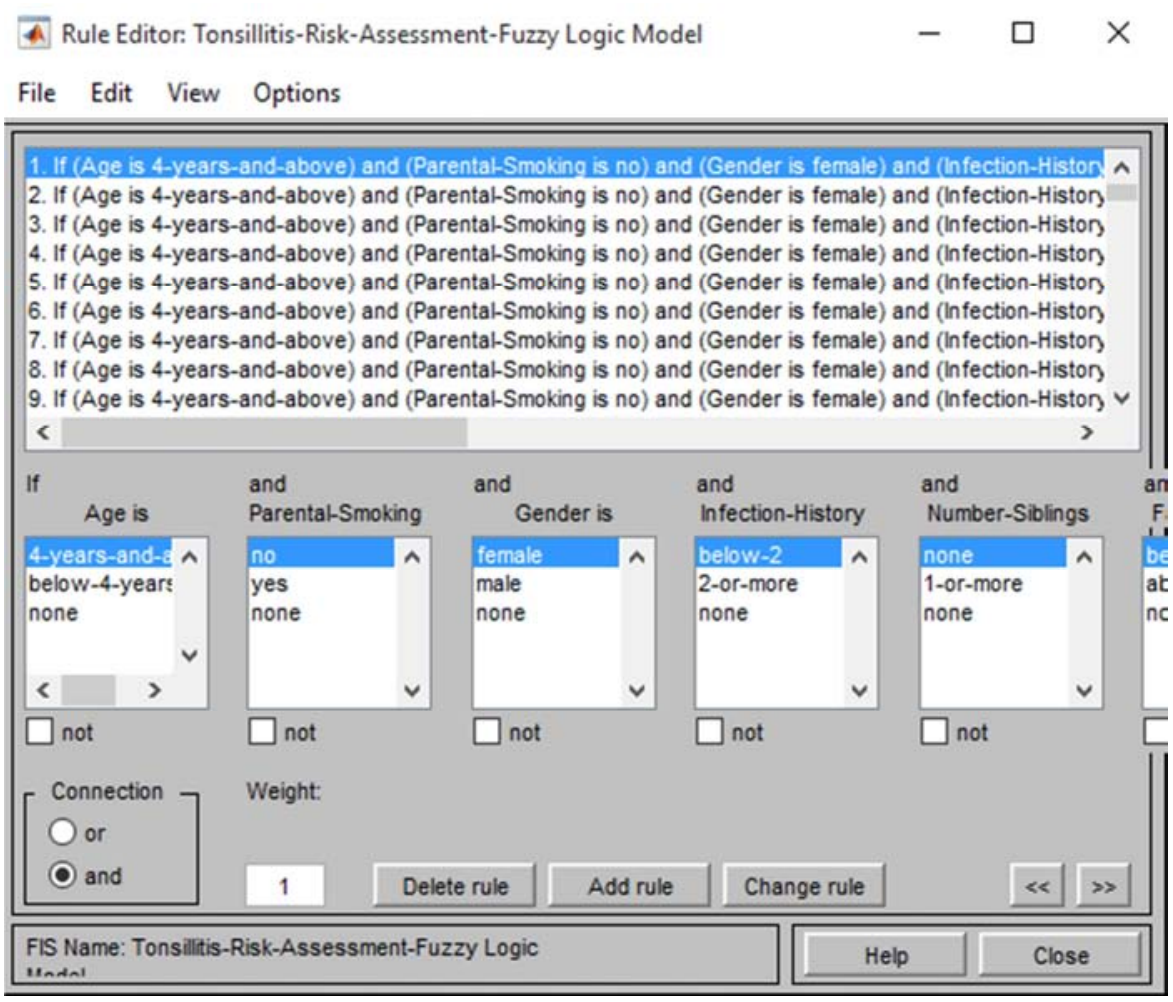

Figure 1. Rule Production on Risk of Recurrent Tonsillitis.

History of throat infections $=\frac{16}{2}=8$

Number of older siblings $=\frac{8}{4}=4$

$$
\text { History of URIs }=\frac{4}{2}=2
$$

Difficult breathing at night $=\frac{2}{2}=1$

The production of rules in the FIS model is described in figure 1 .

\subsection{Simulation of the Formulated Fuzzy Logic Model}

The simulation and analysis of FIS model was done in MATLAB fuzzy logic tool. The developed models were simulated for their functionality and effectiveness after the development of the fuzzy inference system for the prediction of recurrent tonsillitis. The variables were used as inputs for the model which in turn is used for the simulation of the model.

The simulated model was validated using the data collected based on accuracy, true positive rate (TP), false positive rate (FP) and the precision. From 7 patients collected, the data explaining the variables identified for predicting recurrent tonsillitis risk such as age, parental smoking, gender, history of throat infections, number of older siblings, history of URIs and difficult breathing at night including the level of recurrent tonsillitis risk (no risk, low risk, moderate risk and high risk).

\section{Results and Discussion}

This research requires the development of a predictive model for recurrent tonsillitis using the fuzzy logic model via the MATLAB R2016a. The process of implementing the system started with the formulation of the fuzzy logic inference system which was implemented using the MATLAB fuzzy logic Toolbox. The process has been taken and the rule base of the FIS model had been used in completing the development process.

\subsection{Fuzzy Logic Model Formation Results}

The variables which include age, parental smoking, gender, history of infections, number of older siblings with disease, history of URI and difficult breathing at night were formulated using the triangular membership function. Equation 4.1 (a-b) shows the mathematical expression used 
to determine the fuzzified value for variable gender from the crisp values and which applies to other variables

$$
\begin{gathered}
\text { Gender (Female: }-0.5,0,0.5)=\left\{\begin{array}{c}
0, x \leq-0.5 \\
\frac{x+0.5}{0.5}, 0.5<x<0 \\
\frac{0.5-x}{0.5}, 0<x<0.5 \\
0, x \geq 0.5
\end{array}\right\} \\
\text { Gender (Male: } 0.5,1,1.5)=\left\{\begin{array}{c}
0, x \leq 0.5 \\
\frac{x-0.5}{0.5}, 0.5<x<1 \\
\frac{1.5-x}{0.5}, 1<x<1.5 \\
0, x \geq 1.5
\end{array}\right\}
\end{gathered}
$$

\subsection{Simulation Result of the Formulated Fuzzy Logic Model}

The simulated result of the fuzzy logic model was done using MATLAB which involved formulation of the fuzzy logic inference system (FIS) which was carried out by the MATLAB tool. The variables which are the risk factors were used to build the fuzzy logic inference system to determine the risk of recurrent tonsillitis with 7 variables as input and one output which shows the result of the risk of recurrent tonsillitis. Figure 2 shows the FIS file for the risk of recurrent tonsillitis which contains the 7 variables that serves as input and also the tonsillitis risk output.

i. Formulation of age

The age variable was formulated using two triangular membership functions for the labels, below 4 years and 4 years and above. The interval for the membership function was constructed such that the range of the value is between 0 and 1. The graph represents the interval for each of the label which is shown in the params box in the figure. The label below 4 years represents 1 while the other label, 4 years and above represents 0 . Figure 3 show the formulated age variable using triangular membership functions.

ii. Formulation of parental smoking and difficulty breathing at night

Parental smoking and difficulty breathing at night were each formulated using two triangular membership functions for the labels, Yes and No. The graph represents the interval for each of the label which is shown in the params box in the figure. The interval for each membership function was constructed such that the range of the value is between 0 and 1. The label yes represents 1 while the other label, no represents 0 . Figures 4 and 5 show the formulated parental smoking and difficulty breathing at night respectively using triangular membership functions.

iii. Formulation of gender

Gender was formulated using two triangular membership functions for the labels, male and female. The graph represents the interval for each of the label which is shown in the params box in the figure. The interval for the membership function was designed such that the range of the value is between 0 and 1 . The label yes represents 1 while the other label, no represents 0 . Figure 6 shows the formulated gender using triangular membership functions.

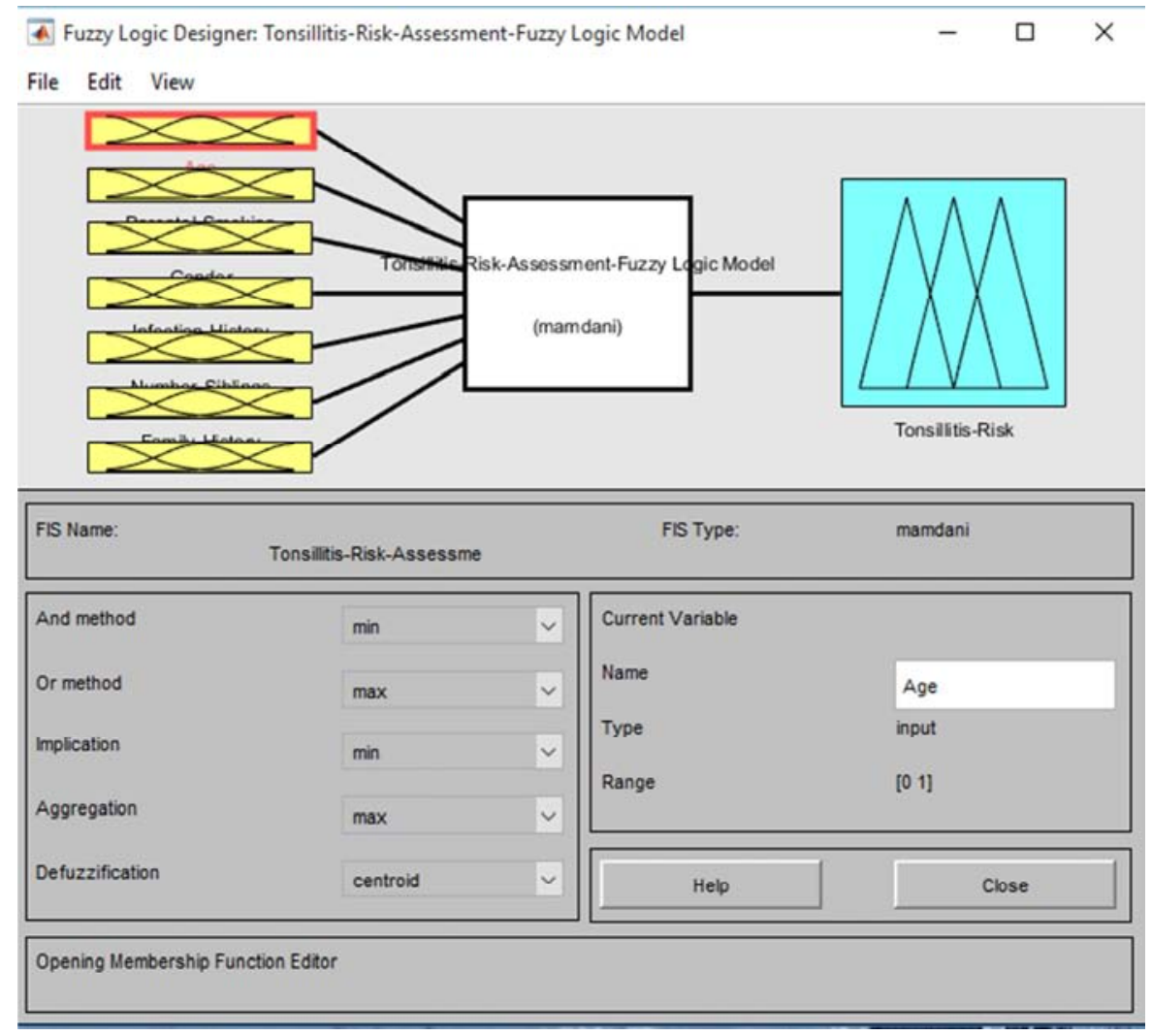

Figure 2. FIS File for Risk of Recurrent Tonsillitis. 
Membership Function Editor: Tonsillitis-Risk-Assessment-Fuzzy Logic M... - $\quad \square \quad \times$ File Edit View

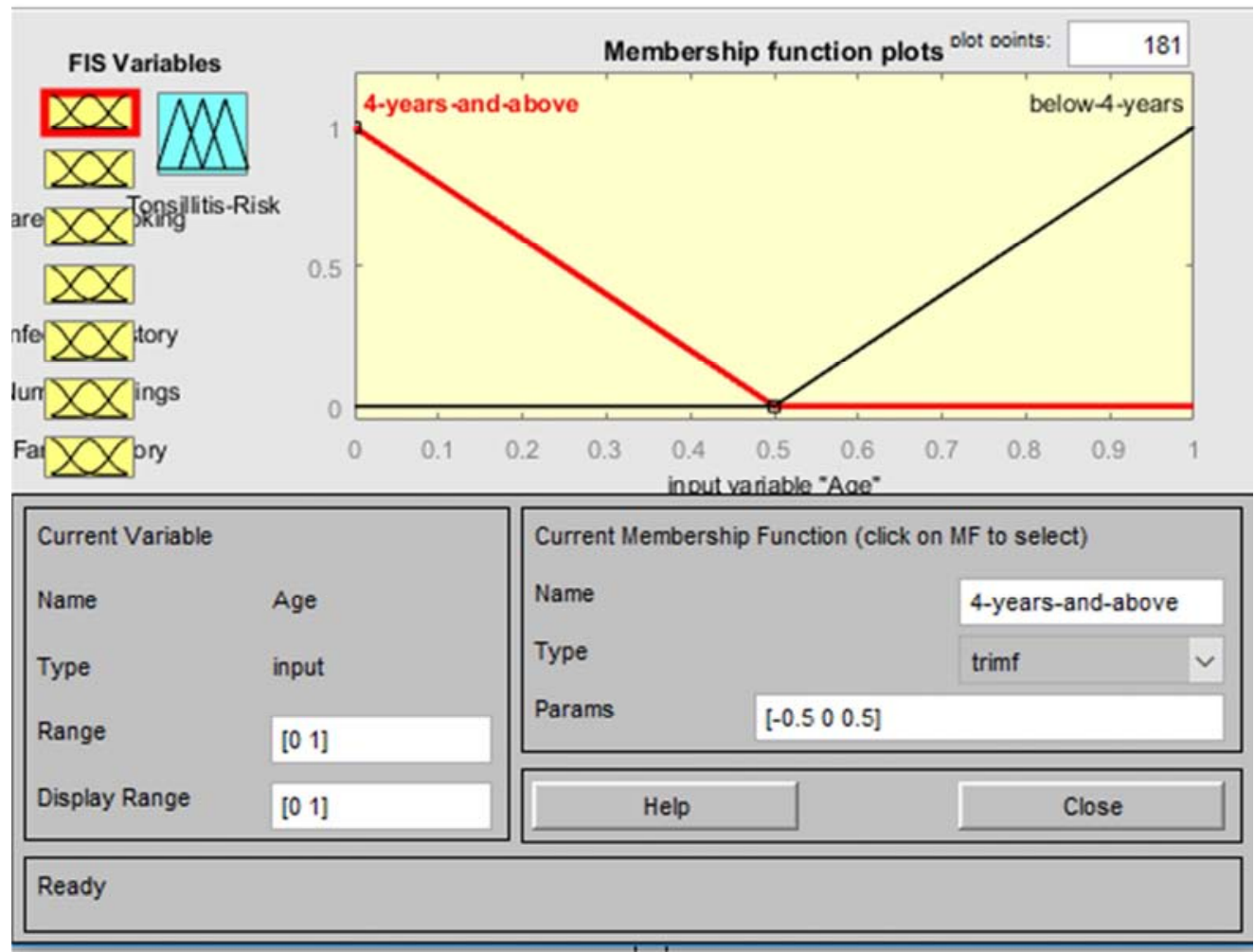

Figure 3. Membership Function of Age.

Membership Function Editor: Tonsillitis-Risk-Assessment-Fuzzy Logic M... - $\quad \square \quad \times$ File Edit View

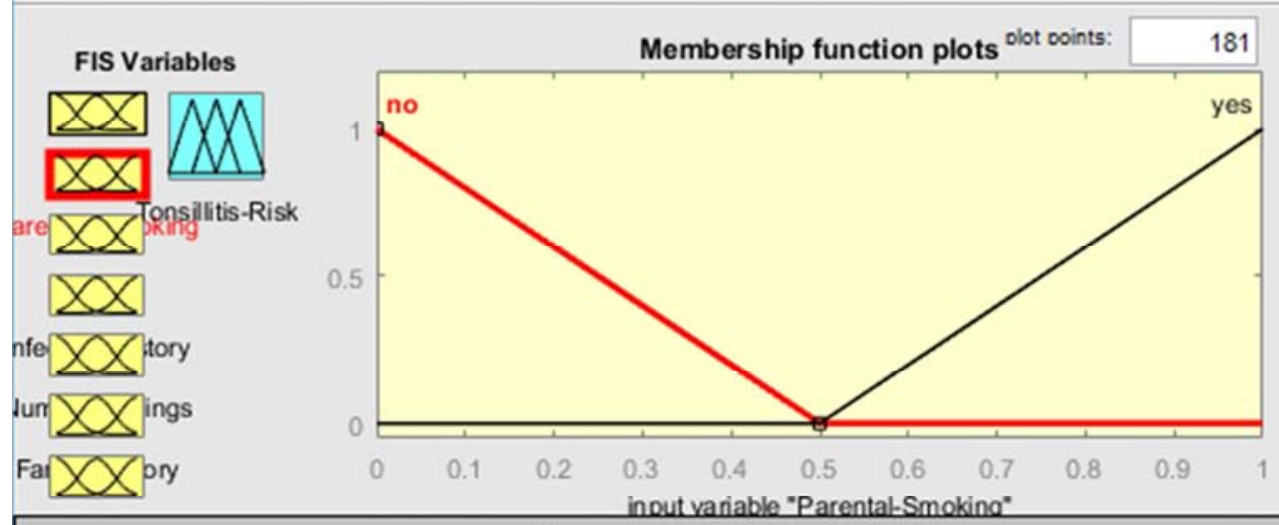

\begin{tabular}{|c|c|c|c|c|c|}
\hline Current Variabl & & \multicolumn{4}{|c|}{ Current Membership Function (click on MF to select) } \\
\hline Name & Parental-Smoking & \multirow{3}{*}{$\begin{array}{l}\text { Name } \\
\text { Type } \\
\text { Params }\end{array}$} & & \multicolumn{2}{|l|}{ no } \\
\hline Type & input & & & trimf & $\checkmark$ \\
\hline Range & {$\left[\begin{array}{ll}0 & 1\end{array}\right]$} & & \multicolumn{3}{|l|}{$\left[\begin{array}{lll}-0.5 & 0 & 0.5\end{array}\right]$} \\
\hline Display Range & {$\left[\begin{array}{ll}0 & 1\end{array}\right]$} & Help & & Close & \\
\hline
\end{tabular}

Selected variable "Parental-Smoking"

Figure 4. Member Function of Parental Smoking. 


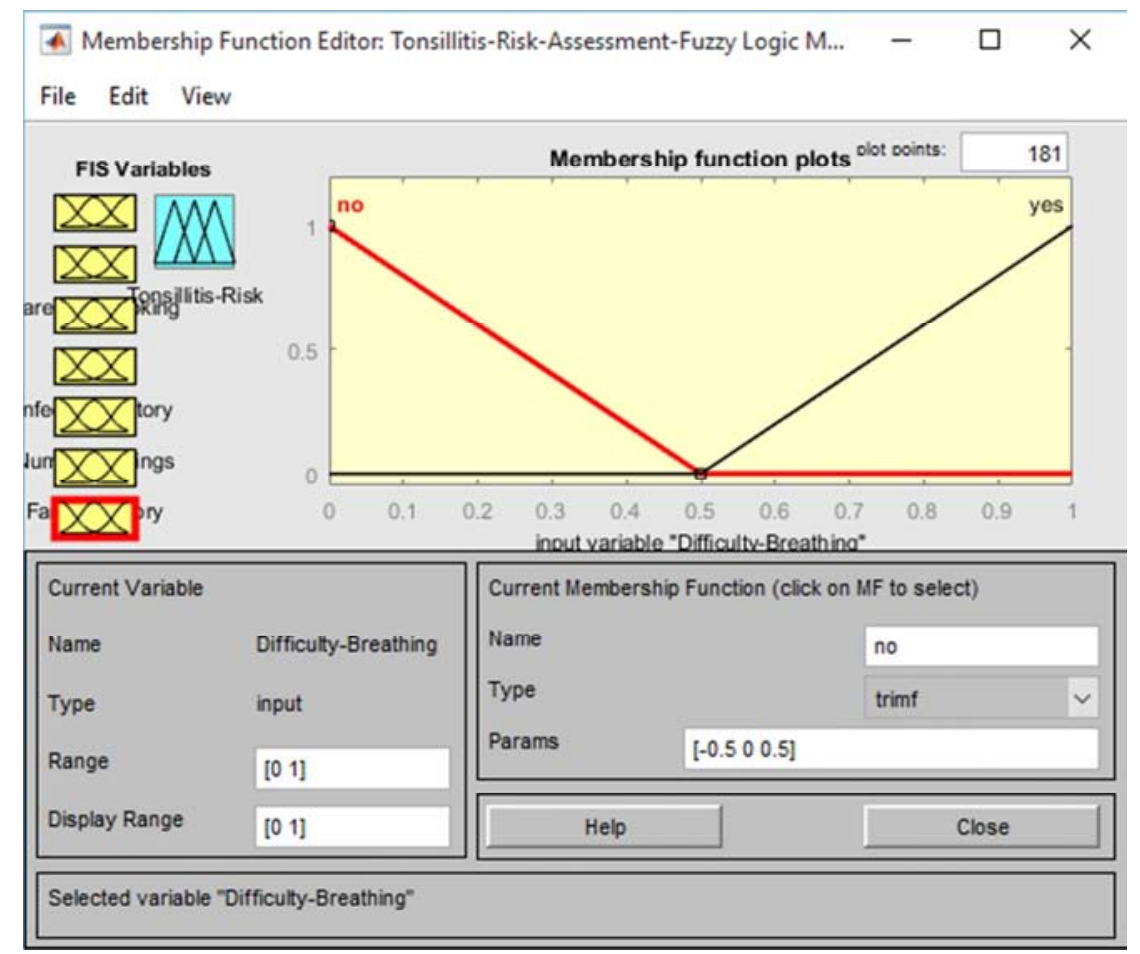

Figure 5. Membership Function of Difficulty Breathing at Night.

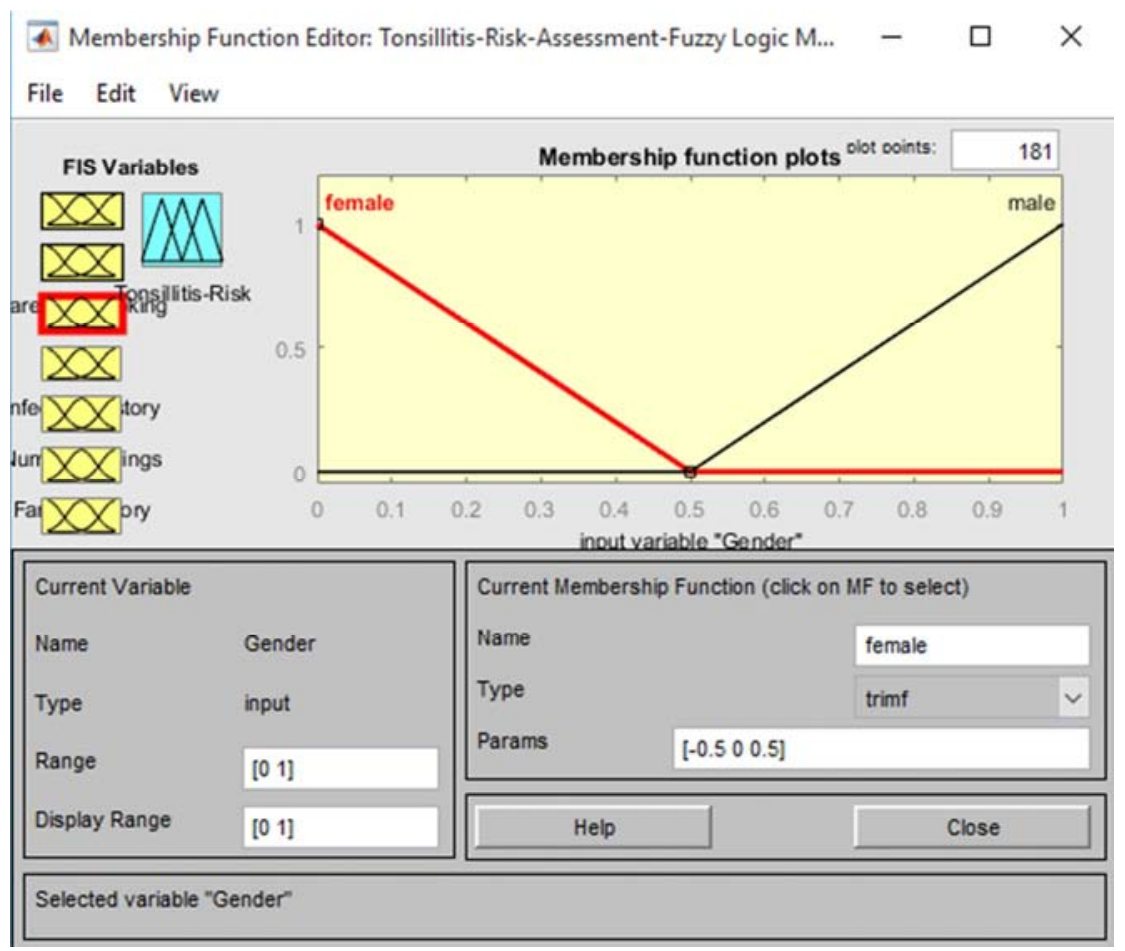

Figure 6. Membership Function of Gender.

iv. Formulation of history of throat infections

History of throat infections was formulated using two triangular membership functions for the labels, below 2 times and 2 or more. The graph represents the interval for each of the label which is shown in the params box in the figure. The interval for the membership function was constructed such that the range of the value is between 0 and 1 . The label below 2 times represents 1 while the other label, 2 or more represents 0 . Figure 7 show the formulated history of throat infections using triangular membership functions.

v. Formulation of number of older siblings with disease Number of older siblings with disease was formulated using two triangular membership functions for the labels, none and 1 or more. The graph represents the interval for each of the label which is shown in the params box in the figure. The interval for the membership function was 
constructed such that the range of the value is between 0 and 1. The label 1 or more represents 1 while the other label, none represents 0 . Figure 8 show the formulated number of older siblings with disease using triangular membership functions.

vi. Formulation of history of upper respiratory infection Upper respiratory infection was formulated using two triangular membership functions for the labels, below 6 and 6 or more. The graph represents the interval for each of the label which is shown in the params box in the figure. The interval for the membership function was designed such that the range of the value is between 0 and 1 . The label 6 or more represents 1 while the other label, below 6 represents 0 . Figure 9 show the history of upper respiratory infection using triangular membership functions.

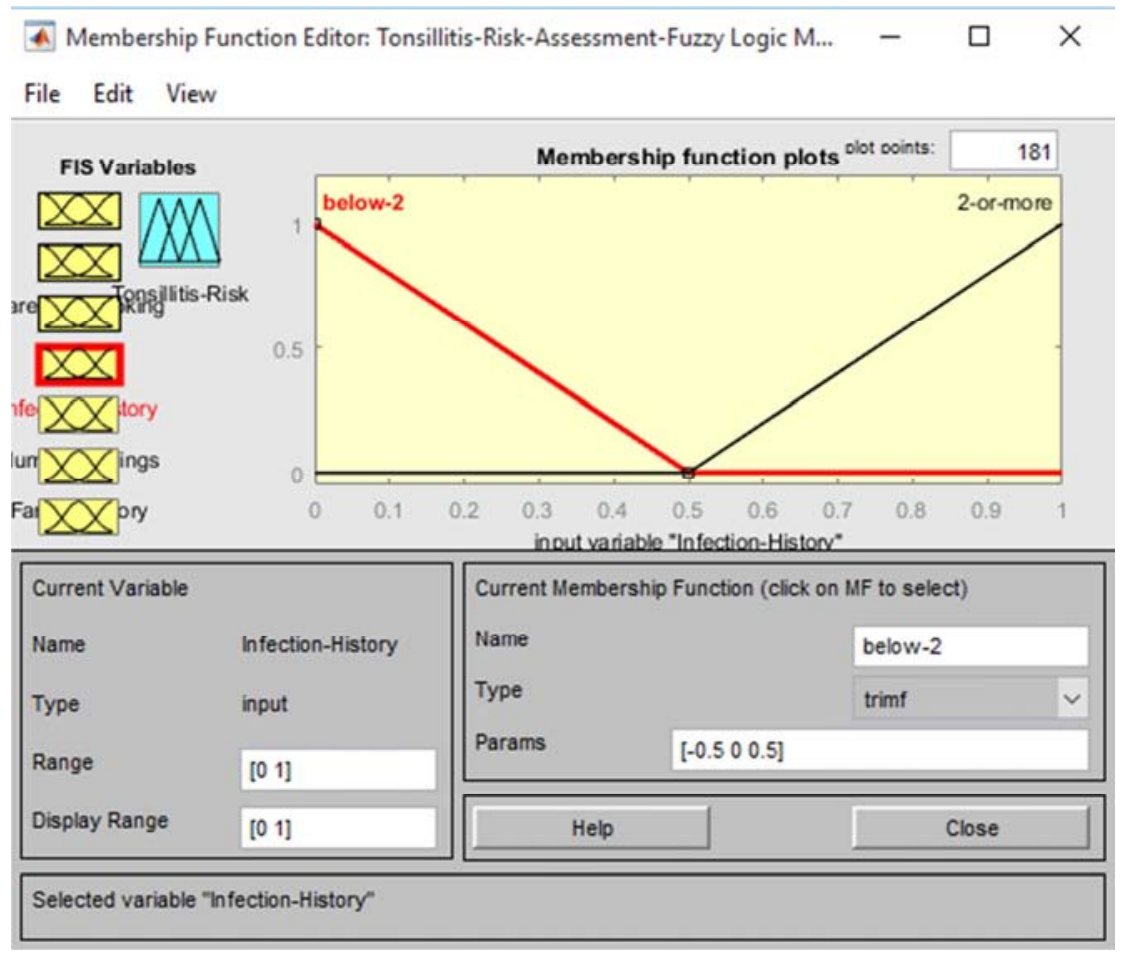

Figure 7. Membership Function of History of Infections.

A Membership Function Editor: Tonsillitis-Risk-Assessment-Fuzzy Logic M... - $\square \times$

File Edit View

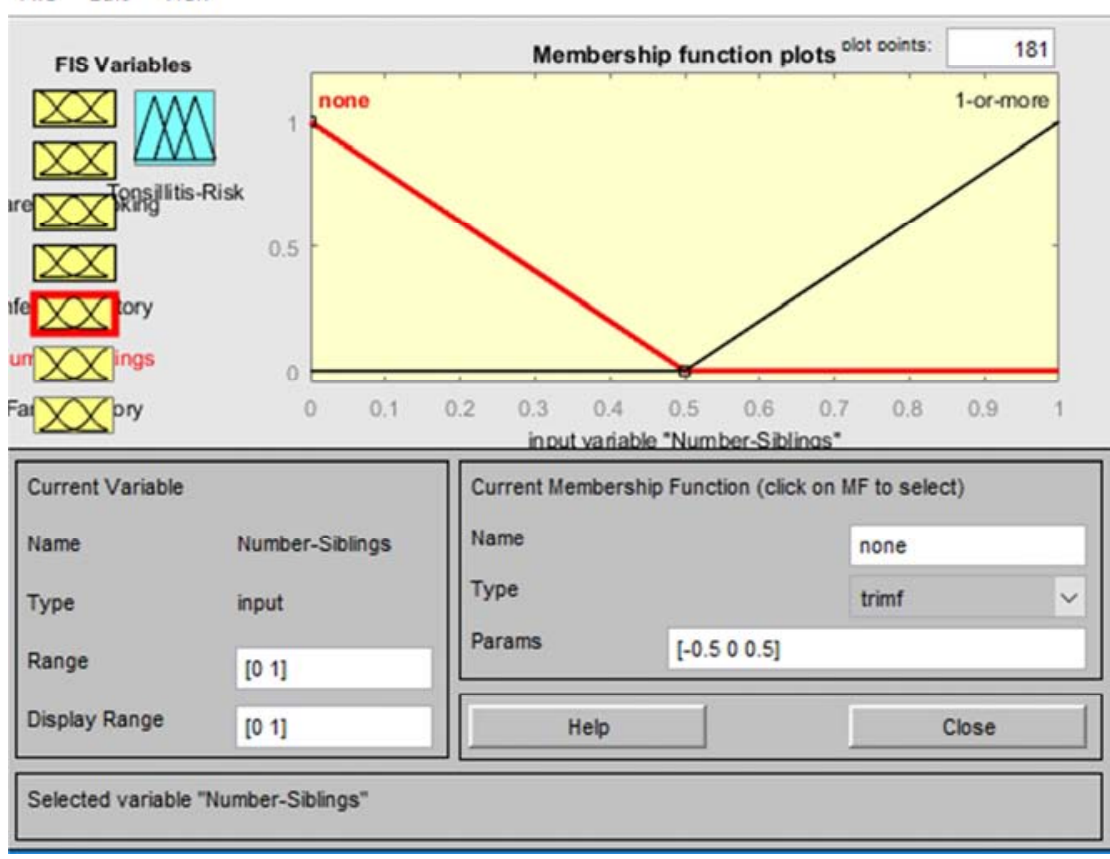

Figure 8. Membership Function of Number of Older Siblings with Disease. 


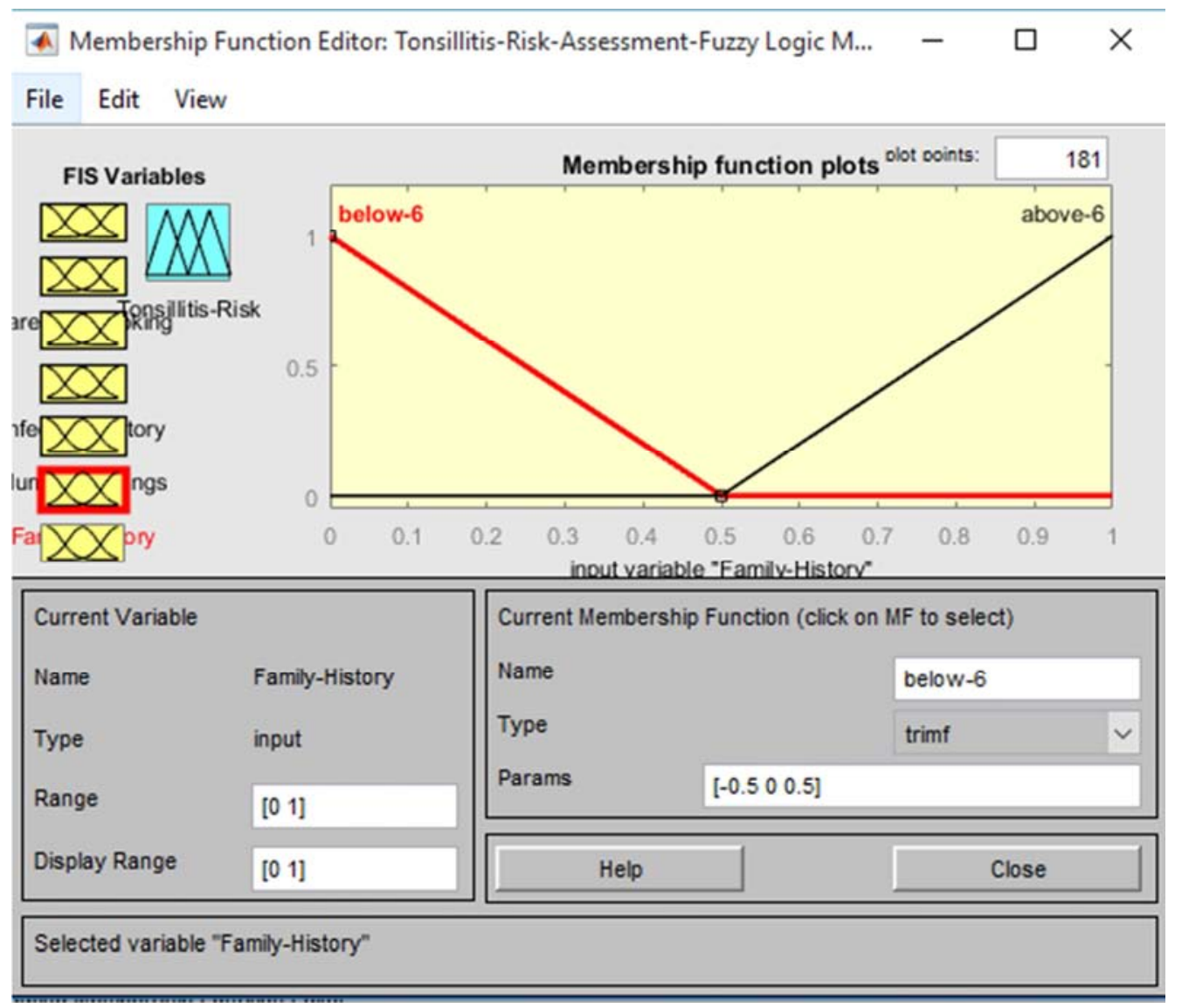

Figure 9. Membership Function of History of URI.

The output of the model is classified as follows:

i. If all the risk factors variable has linguistic value in the interval $\left[\begin{array}{lll}-0.5 & 0 & 0.5\end{array}\right]$, there is no risk of recurrent tonsillitis.

ii. If all the risk factors variables have linguistic value in the interval [ $\left.\begin{array}{lll}0.5 & 1 & 1.5\end{array}\right]$, there is low risk of recurrent tonsillitis.

iii.If all the risk factors variables have linguistic value in the interval [ $\left.\begin{array}{lll}1.5 & 2 & 2.5\end{array}\right]$, there is moderate risk of recurrent tonsillitis.

iv. If all the risk factors variables have linguistic value in the interval [ $\left[\begin{array}{lll}2.5 & 3 & 3.5\end{array}\right]$, there is high risk of recurrent tonsillitis.

\subsection{Validation of the Model}

Validation is the task of demonstrating that the model is a reasonable representation of the actual system. It reproduces system behaviour with enough fidelity to satisfy analysis objectives. For the validation of the model, data were collected from 7 patients which were used to test the efficiency of the formulated model. Table 3 shows the data collected from 7 patients with tonsillitis risk for each of the distribution. Out of the seven (7) patients test data provided, no patients have no risk, there is no high risk of recurrent tonsillitis while five (5) patients have a low risk and two (2) patients have moderate risk of having recurrent tonsillitis.

The distribution was determined by considering age with ages below 4 years and those that are 4 years above, alongside gender with male and female. Based on age group, the result showed that majority of the patients are less than 4 years $(71.43 \%)$ which is twice the number of patients that are greater than 4 years $(28.57 \%)$. And based on gender, the result showed that most of the patients are males $(57.14 \%)$ while female is $42.86 \%$ as shown in table 4 and table 5 .

Table 3. Distribution of Factors assessed from Respondents.

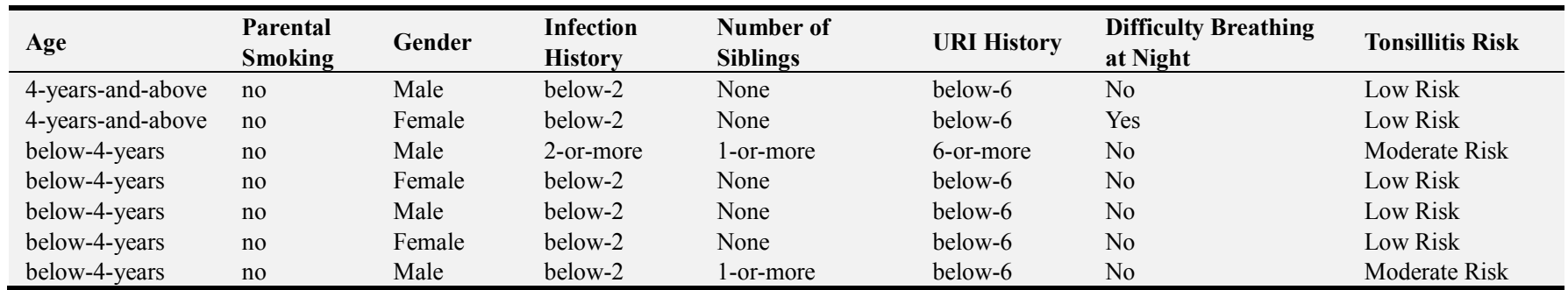


Table 4. Description of Factors assessed Based on Age Group.

\begin{tabular}{|c|c|c|c|c|c|c|c|}
\hline \multirow{2}{*}{ Variables } & \multirow{2}{*}{ Labels } & \multicolumn{2}{|c|}{ below-4-years } & \multicolumn{2}{|c|}{ 4-years and above } & \multirow{2}{*}{$\begin{array}{l}\text { Total } \\
\text { Frequency }\end{array}$} & \multirow{2}{*}{$\begin{array}{l}\text { Total } \\
\text { Percentage (\%) }\end{array}$} \\
\hline & & Frequency & Percentage (\%) & Frequency & Percentage (\%) & & \\
\hline \multirow{2}{*}{ Parental Smoking } & Yes & 0 & 0.00 & 0 & 0.00 & 0 & 0.00 \\
\hline & No & 5 & 71.43 & 2 & 28.57 & 7 & 100.00 \\
\hline \multirow{2}{*}{ Gender } & Male & 3 & 42.86 & 1 & 14.29 & 4 & 57.14 \\
\hline & Female & 2 & 28.57 & 1 & 14.29 & 3 & 42.86 \\
\hline \multirow{2}{*}{ Infection History } & below-2 & 4 & 57.14 & 2 & 28.57 & 6 & 85.71 \\
\hline & 2-or-more & 1 & 14.29 & 0 & 0.00 & 1 & 14.29 \\
\hline \multirow{2}{*}{ Number of Siblings } & none & 3 & 42.86 & 2 & 28.57 & 5 & 71.43 \\
\hline & 1-or-more & 2 & 28.57 & 0 & 0.00 & 2 & 28.57 \\
\hline \multirow{2}{*}{ URI History } & below-6 & 4 & 57.14 & 2 & 28.57 & 6 & 85.71 \\
\hline & 6-or-more & 1 & 14.29 & 0 & 0.00 & 1 & 14.29 \\
\hline \multirow{3}{*}{$\begin{array}{l}\text { Difficulty Breathing } \\
\text { at Night }\end{array}$} & yes & 0 & 0.00 & 1 & 14.29 & 1 & 14.29 \\
\hline & no & 5 & 71.43 & 1 & 14.29 & 6 & 85.71 \\
\hline & No Risk & 0 & 0.00 & 0 & 0.00 & 0 & 0.00 \\
\hline \multirow{3}{*}{ Tonsillitis Risk } & Low Risk & 3 & 42.86 & 2 & 28.57 & 5 & 71.43 \\
\hline & Moderate Risk & 2 & 28.57 & 0 & 0.00 & 2 & 28.57 \\
\hline & High Risk & 0 & 0.00 & 0 & 0.00 & 0 & 0.00 \\
\hline Total & & 5 & 71.43 & 2 & 28.57 & 7 & 100.00 \\
\hline
\end{tabular}

Table 5. Description of Factors assessed Based on Gender.

\begin{tabular}{|c|c|c|c|c|c|c|c|}
\hline \multirow{3}{*}{ Variables } & \multirow{3}{*}{ Labels } & \multicolumn{4}{|l|}{ Gender } & \multirow{3}{*}{$\begin{array}{l}\text { Total } \\
\text { Frequency }\end{array}$} & \multirow{3}{*}{$\begin{array}{l}\text { Total } \\
\text { Percentage (\%) }\end{array}$} \\
\hline & & \multicolumn{2}{|l|}{ Male } & \multicolumn{2}{|l|}{ Female } & & \\
\hline & & Frequency & Percentage (\%) & Frequency & Percentage (\%) & & \\
\hline \multirow{2}{*}{ Parental Smoking } & Yes & 0 & 0.00 & 0 & 0.00 & 0 & 0.00 \\
\hline & No & 4 & 57.14 & 3 & 42.86 & 7 & 100.00 \\
\hline \multirow{2}{*}{ Age Group } & below 4 years & 4 & 57.14 & 1 & 14.29 & 5 & 71.43 \\
\hline & 4 years and above & 0 & 0.00 & 2 & 28.57 & 2 & 28.57 \\
\hline Infection History & below-2 & 3 & 42.86 & 3 & 42.86 & 6 & 85.71 \\
\hline \multirow{2}{*}{ Number of Siblings } & none & 2 & 28.57 & 3 & 42.86 & 5 & 71.43 \\
\hline & 1-or-more & 2 & 28.57 & 0 & 0.00 & 2 & 28.57 \\
\hline \multirow{2}{*}{ URI History } & below-6 & 4 & 57.14 & 2 & 28.57 & 6 & 85.71 \\
\hline & 6-or-more & 0 & 0.00 & 1 & 14.29 & 1 & 14.29 \\
\hline \multirow{3}{*}{$\begin{array}{l}\text { Difficulty Breathing at } \\
\text { Night }\end{array}$} & yes & 0 & 0.00 & 1 & 14.29 & 1 & 14.29 \\
\hline & no & 4 & 57.14 & 2 & 28.57 & 6 & 85.71 \\
\hline & No Risk & 0 & 0.00 & 0 & 0.00 & 0 & 0.00 \\
\hline \multirow{2}{*}{ Tonsillitis Risk } & Low Risk & 3 & 42.86 & 2 & 28.57 & 5 & 71.43 \\
\hline & High Risk & 0 & 0.00 & 0 & 0.00 & 0 & 0.00 \\
\hline Total & & 4 & 57.14 & 3 & 42.86 & 7 & 100.00 \\
\hline
\end{tabular}

Figure 10 shows the fuzzy interface where the values will be inputted for testing dataset and also where the result will be displayed. For the variables used in the validation of the model, the label with high risk of recurrent tonsillitis represents 1 while the label with low risk represent 0 which will be the input values for testing the model as depicted in table 6. In the fuzzy interface, the value for each of the variables represents the values inputted at the input box at the lower part of the figure. The result showed the value of 2 which represents moderate risk of tonsillitis.

After the model was validated, the result was compared with the linguistic variable of tonsillitis risk and the actual tonsillitis risk class described in table 6 and which shows that the validation of the predictive model was valid.

The validated model shows that 5 patients have low risk of tonsillitis, there is no patient with no risk, no patient with high risk while 2 have moderate risk as described in table 7 . After the validation of the data from respondent, the result shows seven (7) correct classifications and no incorrect classification resulting in $100 \%$ accuracy with no error rate as described in table 8 .

\subsection{Discussion}

The fuzzification process of the fuzzified input label of each input variable into their respective fuzzified output variable was achieved in the inference engine of the fuzzy inference system developed. The risk factors constituted the variables that were used to develop the model with 128 rules to define the relationship between the input and output linguistic labels defined.

The predictive model used the values of 7 identified variables associated with recurrent tonsillitis in formulating the model. The triangular membership function was used to formulate the input variables and also the output variable using the process of fuzzification based on the crisp value of the input variables provided. 


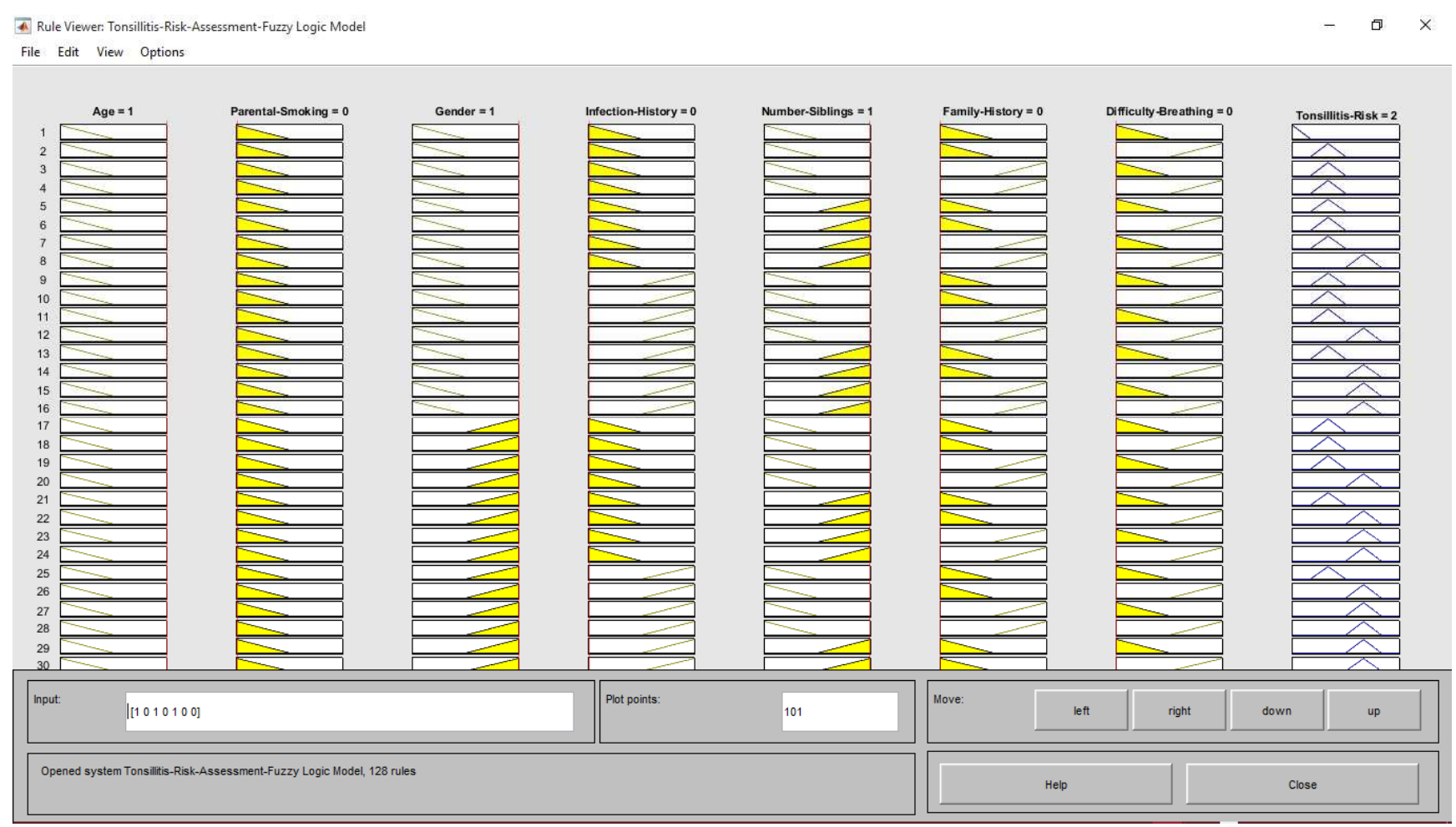

Figure 10. Fuzzy Interface for Testing Dataset.

Table 6. Validation of the Result of the Predictive Model.

\begin{tabular}{llllllllll}
\hline Age & $\begin{array}{l}\text { Parental } \\
\text { Smoking }\end{array}$ & Gender & $\begin{array}{l}\text { Infection } \\
\text { History }\end{array}$ & $\begin{array}{l}\text { Number of } \\
\text { Siblings }\end{array}$ & URI History & $\begin{array}{l}\text { Difficulty } \\
\text { Breathing } \\
\text { at Night }\end{array}$ & $\begin{array}{l}\text { Fuzzy Value } \\
\text { for Tonsillitis } \\
\text { Risk }\end{array}$ & $\begin{array}{l}\text { Linguistic } \\
\text { variable of } \\
\text { Tonsillitis Risk }\end{array}$ & $\begin{array}{l}\text { Actual Tonsillitis } \\
\text { Risk Class }\end{array}$ \\
\hline 0 & 0 & 1 & 0 & 0 & 0 & 0 & 1 & Low Risk & Low Risk \\
0 & 0 & 0 & 0 & 0 & 0 & 1 & 1 & Low Risk & Low Risk \\
1 & 0 & 1 & 1 & 1 & 1 & 0 & 2 & Moderate Risk & Moderate Risk \\
1 & 0 & 0 & 0 & 0 & 0 & 0 & 1 & Low Risk & Low Risk \\
1 & 0 & 1 & 0 & 0 & 0 & 0 & 1 & Low Risk & Low Risk \\
1 & 0 & 0 & 0 & 0 & 0 & 0 & 1 & Low Risk & Low Risk \\
1 & 0 & 1 & 0 & 1 & 0 & 0 & 2 & Moderate Risk & Moderate Risk \\
\hline
\end{tabular}

Table 7. Results of Model Simulation Classification.

\begin{tabular}{lllll}
\hline Classifications & No Risk & Low Risk & Moderate Risk & High Risk \\
\hline Correct & 0 & 5 & 2 & 0 \\
Incorrect & 0 & 0 & 0 & 0 \\
Total & 0 & 5 & 2 & 0 \\
\hline
\end{tabular}

Table 8. Results of Performance Evaluation of Predictive Model.

\begin{tabular}{ll}
\hline Performance Metrics & Value \\
\hline Correct Classifications & 7 \\
Incorrect classifications & 0 \\
Accuracy (\%) & 100.0 \\
Error rate (\%) & 0.0 \\
\hline
\end{tabular}

The following assumptions were used for the model;

i. If all the risk factors variable has linguistic value in the interval $\left[\begin{array}{lll}-0.5 & 0 & 0.5\end{array}\right]$, there is no risk of recurrent tonsillitis.

ii. If all the risk factors variables have linguistic value in the interval [ $\left[\begin{array}{lll}0.5 & 1 & 1.5\end{array}\right]$, there is low risk of recurrent tonsillitis.

iii.If all the risk factors variables have linguistic value in the interval $\left[\begin{array}{lll}1.5 & 2 & 2.5\end{array}\right]$, there is moderate risk of recurrent tonsillitis.

iv. If all the risk factors variables have linguistic value in the interval [ [ llll $\left.\begin{array}{lll}2.5 & 3.5\end{array}\right]$, there is high risk of recurrent tonsillitis.

The result of this study showed that there were 7 variables identified for predicting the recurrence of tonsillitis as identified by the paediatrician. Based on the assumption used for the model, the result showed that majority of the patients $(80 \%)$ had low risk of recurrent tonsillitis which constituted 
more than $50 \%$ of the patients selected while $20 \%$ represents patients with moderate risk of recurrent tonsillitis.

The result of the formulation and validation of the model showed that the labels of the variables identified were modelled using triangular membership functions. The result showed that the 2 triangular membership functions were used to model the two values for each of the variable. Also, the risk of recurrent tonsillitis was classified as no risk, low risk, moderate risk and high risk.

The result showed that the model was formulated and simulated via the MATLAB fuzzy logic Toolbox. The result of the validation of the predictive model was used to evaluate the performance of the model formulated and simulated. Following the results of the model validation, the result shows that 5 patients have a low risk while 2 patients have moderate risk of recurrent tonsillitis. The result also shows seven (7) correct classifications and no incorrect classification resulting in $100 \%$ accuracy with no error rate.

\section{Conclusion}

The predictive model for the recurrent tonsillitis in paediatric patient is found to be of great help to the society. The fuzzy method used was effective as it analyses the risk factors which was used as the prediction model. This model has also provided a means for predicting the risk of recurrent tonsillitis and thus provide a means of reducing the risk of the recurrence.

The predictive model was developed based on the fuzzy model formulated for the risk of recurrent tonsillitis using the data collected as the input variables. The input and output variables were all formulated using the fuzzy membership function, a process called fuzzification. The fuzzified inputs were then processed by the inference engine - a system containing rules that define how the input variables will be manipulated to get the output. The output of the inference engine is usual ly output fuzzified values for all the rules which 128 in this case. The resulting fuzzified output are then suggested to produce one single output membership function which was then defuzzied to determine the crisp value used to map the resulting output value of the recurrent tonsillitis risk.

\section{References}

[1] Spinks, A., Glasziou, P. P., and Del Mar, C. B. (2013). Antibiotics for Sore Throat. Cochrane Database of Systematic Reviews, 11. Van-den-Anker, J. N. (2013). Optimising Management of Fever and Pain in Children. International Journal of Clinical practice, 67 (s178), 26-32.

[2] Van-Staaij, B., Van-den-Akker, E., Rovers, M., Hordijk, G., Hoes, A., and Schilder, A. (2004). Adenotonsillectomy in Children: a Randomised Trial. British Medical Journal. 40 (2), 435-439.

[3] Nuha, S., O. M., R., Rakan, M., Majed, A., Rawan, M., and Saleem, O. (2017). Causes and Treatment of Tonsillitis. The Egyptian Journal of Hospital Medicine, 69 (8): 2975-2980.

[4] Pradeep, K. S. (2012). Acute Tonsillitis - If Left Untreated
Could Cause Several Fatal Complications. Journal of Current Clinical Care, 2: 29-34.

[5] Brandtzaeg, P. (2011). Immune Functions of Nasopharyngeal Lymphoid Tissue. In Recent Advances in Tonsils and Mucosal Barriers of the Upper Airways, 72 (3): 20-24.

[6] Morad, A., sathe, N. A., Francis, D. O., McPheeters, M. L., and Chinnadurai, S. (2017). Tonsillectomy Versus Watchful Waiting for Recurrent Throat Infection: A Systematic Review. Paediatrics, 139 (2): 1-12.

[7] Altamimi, S., Khalil, A., Khalaiwi, K., Milner, R., Pusic, M., and Al Othman, M. (2012). Short-term Late-generation Antibiotics Versus Longer Term Penicillin for Acute Streptococcal Pharyngitis in Children. The Cochrane library, Rev 8: CD004872. Retrieved from http://www.ayurvedic.medicine.org/diseases/tonsillitis.htm [Accessed 12 July, 2018) ]

[8] Ali, M., and Al-Shehri, M. (2014). Incidence and Potential Risk Factors of Post-Tonsillectomy Hemorrhage. Bahrain Medical Bulletin, 36 (3): 204

[9] Chiappini, E., Regoli, M., Bonsignori, F., Sollai, S., Parretti, A., and Galli, L. (2011). Analysis of Different Recommendations from International Guidelines for the Management of Acute Pharyngitis in Adults and Children. Clinical Therapeutics, 33 (1): 48-58.

[10] Spektor, Z. S. -V., Kay, D., and Mandell, D. (2016). Risk Factors for Pediatric Post-tonsillectomy Hemorrhage. International Journal of Pediatric Otorhinolaryngology, 84 (13): 151-155.

[11] Vijayashree, M. S., Viswanatha, B., and Sambamurthy, B. N. (2014). Clinical and Bacteriological Study of Acute Tonsillitis. IOSR Journal of Dental and Medical Sciences, 13 (1): 37-43.

[12] Reid, D., Mortan, R., Salkein, L., and Bartely, J. (2011). Vitamin D and Tonsil Disease: Preliminary Observations. International Journal of Paediatric Otorhinolaryngology, 75 (2): 2614

[13] Sarah, Y., Sabry, A., and Esteglal, E. (2014). Isolation and Identification of Microorganisms Causing Tonsillitis among Children of Hail Region. International Journal of Health Sciences and Reseacrh, 100 (4): 125-129.

[14] Zhang, P., Schmidt, D. C., White, J., and Lenz, G. (2018). Chapter One - Blockchain Technology Use Cases in healthcare. Advances in Computer, 111: 1-41.

[15] Rampratap, T. (2016). Modeling for Fault Tolerance in Cloud Computing Environment. Journal of Computer Sciences and Applications, 40 (4): 9-13.

[16] Desikan, P. and Khare, R. (2013). Data Mining for Healthcare: Workshop Summary. International Conference on Health Informatics. Philadelphia, PA.

[17] Butler, C., Hood, K., Kinnersley, P., Robling, M., Prout, H., and Houston, H. (2005). Predicting the Clinical Course of Suspected Acute Viral Upper Respiratory Tract Infection in Children. Family Practice, 22 (1):, 92-95.

[18] Moore, M., Stuart, B., Little, P, Smith, S., Thompson, M. J., Knox, K., van den Bruel, A., Lown, M. and Mant, D. (2017). Predictors of Pneumona in Lower Respiratory Tract Infections: 3C Prospective Cough Complication Cohort Study. European Respiratory Journal, 50: 1-9. 
[19] Cohen, J. F., Cohen, R., Bidet, P., Elbez, A., Levy, C., Bossuyt, P. M and Chalumeau, M. (2017). Efficiency of a Clinical Prediction Model for Selective Rapid Testing in Children with Pharyngitis: A Perspective, Multicenter Study. PLOS One, 12 (2): 1-11.

[20] Aalbers, J., O'brien, K. K., Chan, W., Falk, G. A., Teljeur, C., Dimitrov, D., and Fahey, T. (2011). Predicting Streptococcal Pharyngitis in Adults in Primary Care: A SystematicReview of the Diagnostic Accuracy of Symptoms and Signs and Validation of the Center Score. BMC Medicine, 9 (67): 1-11.

[21] Attia, M. (1999). Multivariate Predictive Models for Group A Beta-hemolytic Streptococcal Pharyngitis in Children. Academy Emergency Medicine, 20 (2): 813-820. 